\title{
Effect of Recycled Powder on Properties of Cement Morta
}

\author{
Yanxing Zhang ${ }^{1}$, Tongheng Zhang ${ }^{1}$, Zhiwu $\mathrm{Liu}^{2,}{ }^{*}$ and Chaoqun $\mathrm{Ma}^{3}$ \\ ${ }^{1}$ Zhejiang Jincheng Construction Group Co., Ltd., Jinhua, China \\ ${ }^{2}$ Architectural Engineering Institue, Jinhua Polytechnic, Jinhua, China \\ ${ }^{3}$ Zhongtian Construction Group Co., Ltd. Hangzhou, China
}

\begin{abstract}
The effects of two types of recycled micro-powder (concrete powder and brick powder) replacing part of cement on the mechanical properties of cement mortar were studied. The results show that the contribution of recycled concrete powder to concrete strength is slightly stronger than that of brick powder. In a certain range of dosage, the performance of recycled concrete powder is close to that of pure cement. When the content of recycled concrete powder is less than $10 \%$, the compressive strength and flexural strength of cement mortar will not be greatly affected: over $20 \%$ cement mortar strength will decrease significantly. When the grinding content of recycled concrete is $5 \%$, the strength of cement mortar is even increased by $4.5 \%$.The relationship between recycled brick powder content and cement mortar strength is almost linear to $20 \%$ limit. The more recycled brick powder content is, the more obvious the cement mortar strength decreases. The particle size of regenerated powder has a certain influence on its activity. After a certain time of ball milling, the activity of regenerated powder can be effectively increased, but the ball milling time is too long, resulting in very fine particles. The activity of regenerated powder increases slightly with the increase of ball milling time, but the effect gradually decreases after more than $1 \mathrm{~h}$.
\end{abstract}

\section{Introduction}

With the acceleration of urbanization in China, the number of construction waste continues to increase, accounting for $30 \% \sim 40 \%$ of the total urban waste [1-2]. Traditional landfill researchers have proposed recycling construction waste into aggregates to mitigate the negative impact of construction waste on the environment. However, in the process of recycling, recycled powder (RCR) with particle size less than $150 \mu \mathrm{m}$ was found in the mixture of waste sintered clay brick and concrete, accounting for $20 \% \sim 35 \%$ of the waste mixture [3], which caused great pollution to air and water. However, some researchers found that RCR has pozzolanic effect and can be used as a supplementary cementitious material to replace some cement, which can promote the hydration rate of cement [4]. KIM and CHOI [5] have found that RCRhas a high content of $\mathrm{SiO}_{2}$, and the smaller the particle

\footnotetext{
*Corresponding author: liuzhiwu645@qq.com
} 
size of RCR, the higher its pozzolanic activity. Cement produced by a South Korean company using recycled micro-powder from waste concrete has the same strength as ordinary Portland cement, but at a lower cost [6]. Xu and Deng research [7] shows that recycled micro-powder can be used as the main raw material to produce recycled cement. The research on recycled micro-powder in China started late, and the research direction is mainly to stimulate the activity of recycled micro-powder, and the impact of the mechanical properties, working performance and durability of recycled concrete prepared as mineral admixtures [7-8]. Some researchers have conducted in-depth studies on the activity of the regenerated micro-powder, and confirmed that its activity can be stimulated by physical and chemical methods. The research of studies showed that the regenerated micro-powder has irregular particles and uneven particle size, and can be used as an admixture to prepare high-strength cement mortar after being ground by a ball mill [9-10]. Due to the small particle size and certain activity of regenerated micro-powder, the most researched one is as a mineral admixture instead of cementing material [11]. Considering the economic cost and energy consumption factors of industrial production of regenerated micro-powder, the utilization of resources is relatively high. Therefore, how to effectively stimulate the activity of the regenerated micro-powder, replace the gelling material with the best ratio, and improve the recycling efficiency of the regenerated micro-powder has high research value.

\section{Experiment}

\subsection{Preparation of recycled powder}

Use a universal crusher to preliminarily crush the waste concrete blocks, and manually crush the initially crushed concrete blocks and broken bricks to small pieces with a diameter of less than 40mm, and then use the SP-100x100 jaw crusher (Figure 1) to crush the materials and collect them, The recycled micro-powder produced in the screening process is RCP (recycled concrete powder) and RBP (recycled brick powder) used in subsequent tests.

\subsection{Experiment material}

Recycled micro-powder; cement: Red Lion 32.5R cement; sand: China ISO standard sand manufactured by Xiamen Aion Europe; water: tap water.

\subsection{Test objectives and schemes}

In order to determine the effective blending ratio of recycled micro-powder in cement mortar (CRM), and the impact of micro-powder particle fineness on CRM performance. The test in this paper is carried out in accordance with the GB/T17671-1999 cement mortar strength test method for strength determination.

Two kinds of regenerated micro-powders were prepared with different blending ratios in CRM, and $40 \mathrm{~mm} \times 40 \mathrm{~mm} \times 160 \mathrm{~mm}$ cement mortar test blocks were prepared, cured for 24 hours under laboratory conditions, and transferred to a standard curing box after demolding, cured under standard conditions, and measured cement compressive strength and flexural strength of glue sand $7 \mathrm{~d}, 14 \mathrm{~d}, 28 \mathrm{~d}$. At the same time, a particle fineness control group was set up, and the CRM containing the ball-milled RCP and RBP were cemented with the same mix ratio. According to the strength test results, the influence of the fineness of the fine powder on the performance of the CRM was analyzed. 


\section{$3 \mathrm{Mix}$ ratio and strength test results}

In the experiment, the blending ratio of recycled micro-powder is selected to account for $0 \%, 5 \%, 10 \%, 20 \%$, and $50 \%$ of the total CRM quality; the fineness control group selects the CRM with the micro-powder content of $10 \%$ as the basis, and the ball milling is set for $1 \mathrm{~h}, 2 \mathrm{~h}$ for the two control groups, the experimental group settings are shown in Table 1, and the particle size analysis results are shown in Figure 1.

Table 1. Setting table of CRM mortar test group

\begin{tabular}{c|c|c|c|c|c}
\hline \multirow{2}{*}{ Ball milling time(h) } & \multicolumn{6}{|c}{ Dosage(\%) } \\
\cline { 2 - 6 } & 0 & 5 & 10 & 20 & 50 \\
\hline 0 & $\boldsymbol{V}$ & $\boldsymbol{V}$ & $\boldsymbol{V}$ & $\boldsymbol{\checkmark}$ & $\boldsymbol{\checkmark}$ \\
\hline 1 & & & $\boldsymbol{V}$ & & \\
\hline 2 & & & $\boldsymbol{V}$ & & \\
\hline
\end{tabular}

The ratio of cement: sand: water in cement mortar is 2: 6: 1. Compare and analyze according to the measurement results. The intensity test results are shown in Table 2 .

Table 2. CRM cement mortar mix ratio table

\begin{tabular}{|c|c|c|c|c|c|c|c|}
\hline \multirow{2}{*}{$\begin{array}{l}\text { Micro-powder } \\
\text { type }\end{array}$} & \multirow{2}{*}{$\begin{array}{l}\text { Micro- } \\
\text { powder } \\
\text { content }\end{array}$} & \multicolumn{2}{|c|}{$7 \mathrm{~d}$} & \multicolumn{2}{|c|}{$14 \mathrm{~d}$} & \multicolumn{2}{|c|}{$28 \mathrm{~d}$} \\
\hline & & $\begin{array}{c}\text { Compressive } \\
\text { strength }\end{array}$ & $\begin{array}{l}\text { Flexural } \\
\text { strength }\end{array}$ & $\begin{array}{l}\text { Compressive } \\
\text { strength }\end{array}$ & $\begin{array}{l}\text { Flexural } \\
\text { strength }\end{array}$ & $\begin{array}{l}\text { Compressive } \\
\text { strength }\end{array}$ & $\begin{array}{l}\text { Flexural } \\
\text { strength }\end{array}$ \\
\hline \multirow{7}{*}{$\begin{array}{l}\mathrm{RCP}(\text { concrete } \\
\text { powder) }\end{array}$} & 0 & 16.25 & 2.60 & 22.02 & 3.47 & 32.33 & 3.75 \\
\hline & $5 \%$ & 16.85 & 2.37 & 24.36 & 3.43 & 33.78 & 3.50 \\
\hline & $10 \%$ & 15.24 & 2.20 & 21.84 & 2.22 & 31.46 & 3.28 \\
\hline & $20 \%$ & 14.56 & 2.08 & 19.72 & 2.12 & 27.01 & 3.11 \\
\hline & $50 \%$ & 7.54 & 0.78 & 9.31 & 1.50 & 12.24 & 1.52 \\
\hline & 0 & 16.20 & 2.12 & 22.04 & 2.75 & 32.05 & 3.42 \\
\hline & $5 \%$ & 15.42 & 2.15 & 20.73 & 2.58 & 29.59 & 3.62 \\
\hline \multirow{3}{*}{$\begin{array}{l}\text { RBP(Brick } \\
\text { powder) }\end{array}$} & $10 \%$ & 11.57 & 2.08 & 19.29 & 2.13 & 25.42 & 3.17 \\
\hline & $20 \%$ & 10.65 & 1.98 & 17.62 & 2.01 & 23.35 & 2.98 \\
\hline & $50 \%$ & 4.71 & 0.88 & 6.51 & 1.07 & 10.08 & 1.50 \\
\hline $\begin{array}{l}\text { Ball milling } 1 \mathrm{~h} \\
\mathrm{RCP}\end{array}$ & $10 \%$ & 20.96 & 2.35 & 29.71 & 2.93 & 35.09 & 3.70 \\
\hline $\begin{array}{l}\text { Ball milling } 2 \mathrm{~h} \\
\mathrm{RCP}\end{array}$ & $10 \%$ & 21.67 & 2.42 & 26.34 & 2.80 & 34.09 & 3.85 \\
\hline $\begin{array}{l}\text { Ball milling } 1 \mathrm{~h} \\
\text { RBP }\end{array}$ & $10 \%$ & 13.02 & 1.61 & 21.42 & 2.60 & 29.23 & 3.37 \\
\hline $\begin{array}{l}\text { Ball milling } 2 \mathrm{~h} \\
\text { RBP }\end{array}$ & $10 \%$ & 14.67 & 2.02 & 22.32 & 2.74 & 24.27 & 3.42 \\
\hline
\end{tabular}




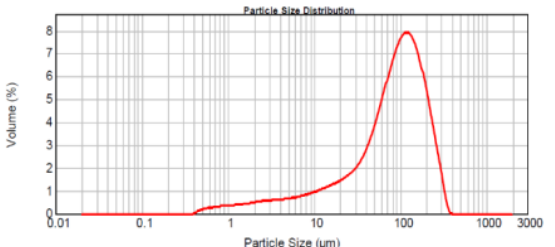

Figure 1-a(1) RCP particle size distribution diagram $(0 \mathrm{~h})$

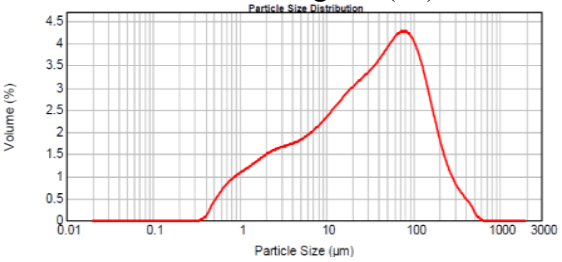

Figure 1-b(1) RCP particle size distribution diagram (1h)

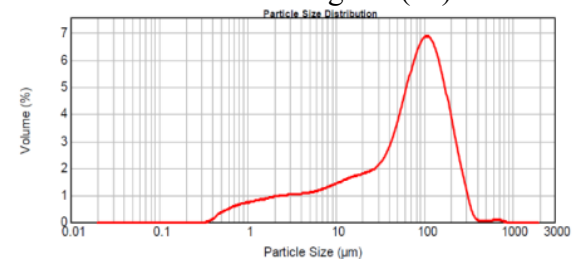

Figure 1-c(1) RCP particle size distribution diagram $(2 \mathrm{~h})$

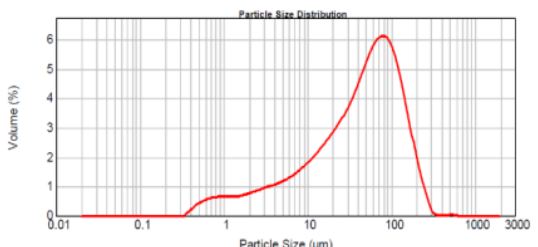

Figure 1-a(2) RBP particle size distribution diagram $(0 \mathrm{~h})$

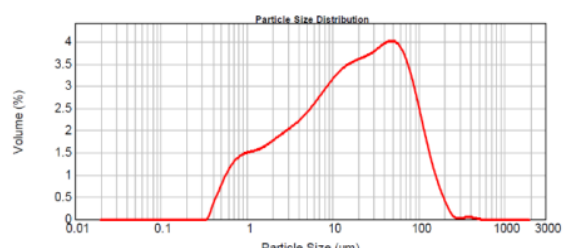

Figure 1-b(2) RBP particle size distribution diagram $(1 \mathrm{~h})$

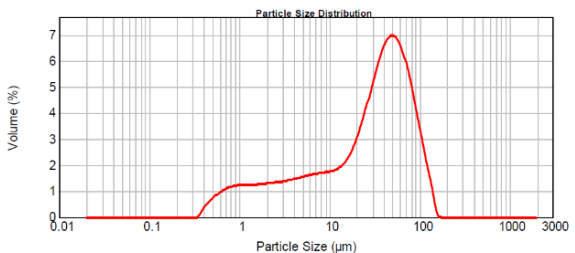

Figure 1-c(2) RBP particle size distribution diagram $(2 \mathrm{~h})$

Fig.1. Particle size distribution of recycled micropowder

\section{Test results and analysis}

\subsection{Influence of recycled micronized powder content on strength of cement mortar}

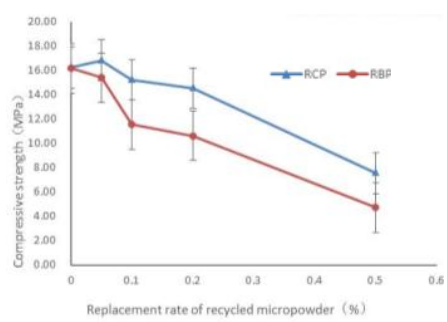

(a) 7 days

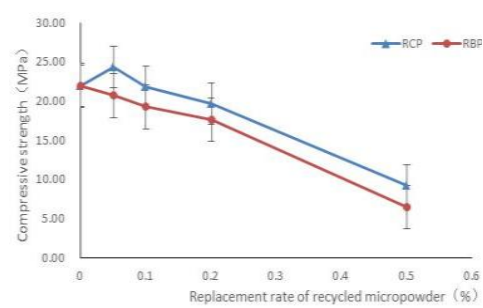

(b) 14 days

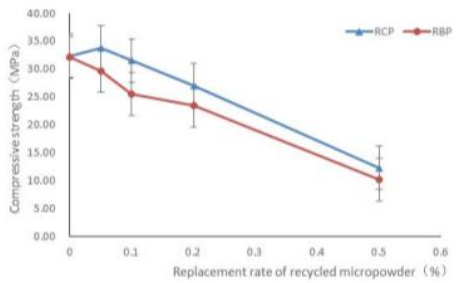

(c) 28 days

Fig.2 Compressive strength of CRM mortar 


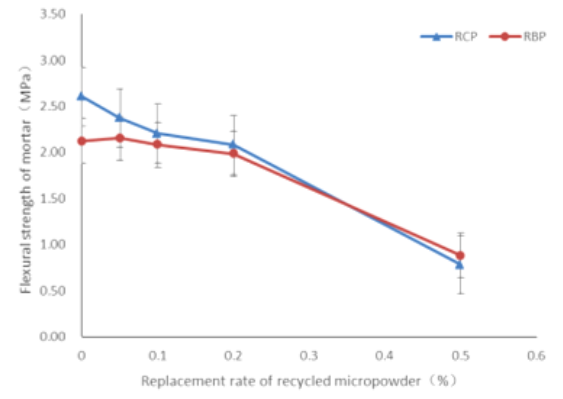

(a) 7 days

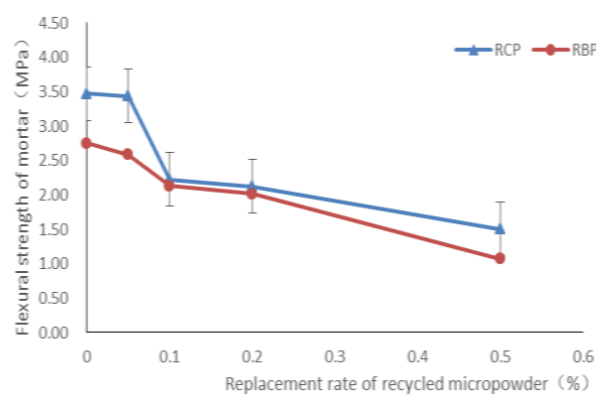

(b) 14 days

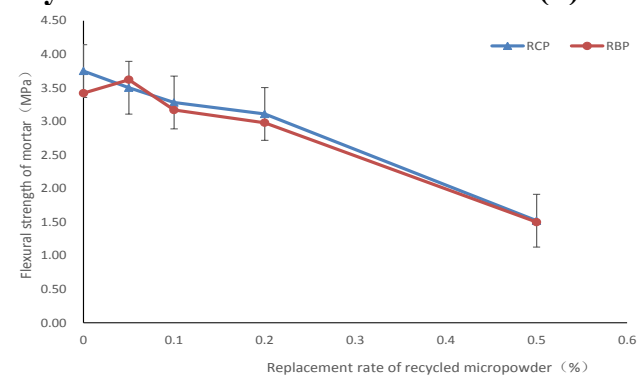

(c) 28 days

Fig.3 Fracture strength of CRM mortar

According to Figure 2 and Figure 3, it can be concluded that, as a whole, as the content of recycled micro-powder in CRM increases, the mechanical properties of cement mortar will gradually weaken. When the content of recycled micro-powder in CRM reaches $50 \%$, cement mortar compared with pure cement mortar, its mechanical properties are reduced by more than $60 \%$, and its properties are seriously deteriorated. This is because the content of lime content in the recycled micro-powder that can undergo hydration reaction is much less than that in cement. It shows that its hydration activity is also compared with cement. It is weak, and some un-hydrated particles in the regenerated micro-powder are wrapped by the consolidated mortar and fail to contact with water to react. Therefore, when the content of regenerated micro-powder gradually increases, the hydration performance of CRM gradually decreases. It can be found from the results of electron microscopy that with the increase in the amount of regenerated fine powder, the C-S-H gel produced in the cement mortar is significantly reduced.

In the case of the same content of recycled micro-powder in CRM, the strength of cement mortar of RCP is slightly higher than that of cement mortar mixed with RBP. When using CRM with RBP content below $10 \%$, the strength of cement mortar is not much different from that when pure cement is used, and the compressive and flexural strength can reach more than $90 \%$ of pure cement mortar; when the content is $5 \%$, it even promotes the strength of cement mortar. The experiment shows that the mechanical properties of cement mortar are more sensitive to the amount of RBP. When the amount is less than $20 \%$, the strength of cement mortar decreases almost linearly with the content of RBP. The strength of cement mortar decreased significantly.

This shows that the hydration activity of RBP is slightly lower than that of RCP. This is because the active ingredients in the brick powder are mostly consumed during the sintering process, and the remaining activity is relatively limited. 


\subsection{The influence of CRM on the strength growth of cement mortar}

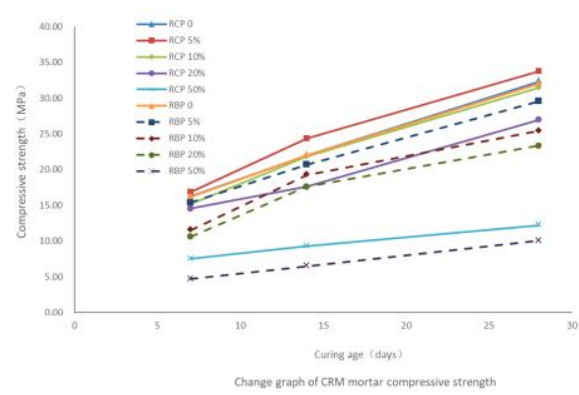

Fig. 4 Chart of compressive strength of CRM mortar

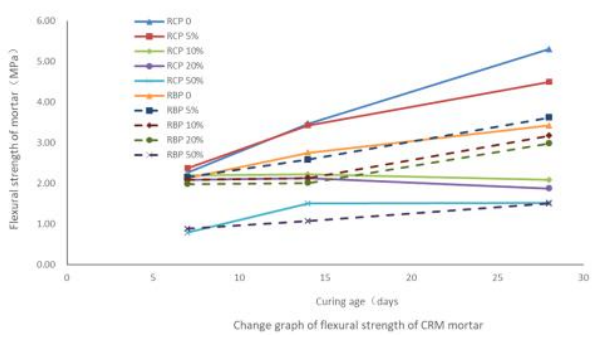

Fig. 5 Diagram of flexural strength of RM mortar

It can be seen from Figures 4 and 5 that when the content of recycled micro-powder is less than $20 \%$, the recycled micro-powder can promote the early strength growth of cement mortar, and the strength growth from $7 \mathrm{~d}$ to $14 \mathrm{~d}$ is increased by about $7 \%$. This may be because the regenerated micro-powder particles are relatively fine, and the hydration reaction rate in the early stage is relatively fast, and then because the proportion of active ingredients in the micro-powder is lower than that of cement, the strength growth in the later stage is gradually slowing down. When the amount of recycled fine powder is too large $(50 \%)$, it can be seen that the strength of cement mortar increases slowly, and it is much lower than that of cement mortar without adding fine powder.

\subsection{Influence of Recycled Micro-powder particle size on CRM performance}

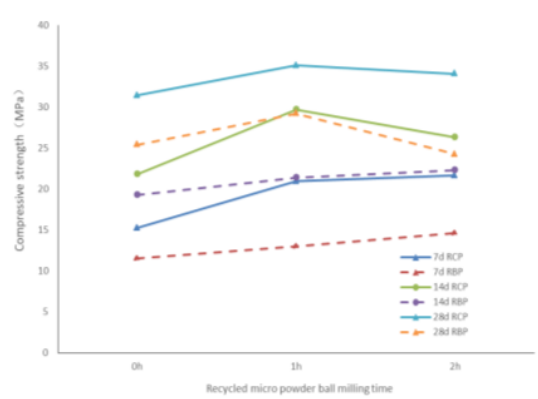

Fig. 6 Effect of milling time on compressive strength of CRM mortar

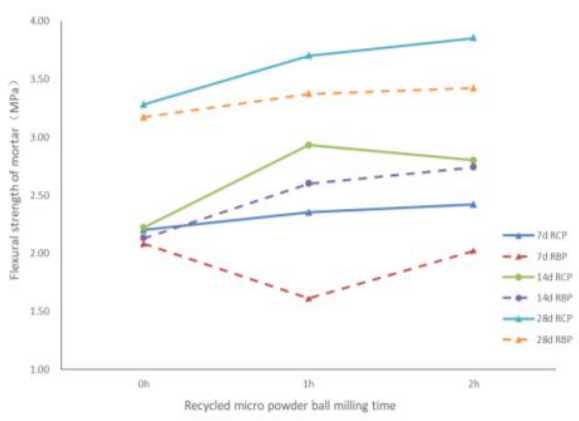

Fig. 7 Effect of milling time on flexural strength of CRM mortar

In order to explore the influence of the particle size of the regenerated micro-powder on the CRM performance, in the experiment, a part of the regenerated micro-powder was ball milled to change its particle size. Then, the cement mortar was prepared, and the strength changes were measured as shown in Figures 6 and 7. It can be seen from figures 6 and 7 that changing the particle size of the regenerated fine powder by a ball mill can increase the activity of the regenerated fine powder to a certain extent: the CRM containing the regenerated fine powder after ball milling is less finely ground, which can improve the strength of the cement mortar to a certain extent. it was found that the RCP for $1 \mathrm{~h}$ of ball milling showed stronger activity than that for $2 \mathrm{~h}$ of ball milling, and the compressive strength of cement mortar increased by more value. This may be due to the fact that some active ingredients in RCP are wrapped by other hydration products, which are exposed after 
ball milling, which is easy for hydration reaction to occur. After the outer particles are refined, the specific surface area of the material is increased, and it can also improve a certain activity; however, when the particles are too fine, it may reduce the density of the void filling in the cement mortar, resulting in a decrease in strength. RBP can also increase its activity after ball milling, and the activity increases with the increase of ball milling time. When it exceeds $1 \mathrm{~h}$, the proportion of activity increase gradually decreases. This may be because the activity of RBP is mainly related to the particle size.

\section{Conclusion}

Construction waste regenerated micro-powder has a certain potential activity. The regenerated micro-powders from different sources has different activities, and their properties are quite different. Experimental research shows that when the activity of recycled micro-powder is characterized based on the mechanical properties of concrete, the contribution of recycled concrete micro-powder (RCP) to the strength of concrete is slightly stronger than that of brick powder (RBP). The activity of the regenerated micro-powder is mainly related to its chemical composition, the content of un-hydrated calcareous particles and the particle fineness. Within a certain dosage range, the performance of CRM is close to that of pure cement. When the content of recycled fine powder in CRM is within $10 \%$, the compressive strength and flexural strength of cement mortar will not be greatly affected; when the content of recycled fine powder exceeds $20 \%$, the strength of cement mortar will decrease significantly. When the amount of RCP is $5 \%$, the strength of cement mortar is even increased by $4.5 \%$; the amount of BRP and the strength of cement mortar change almost linearly, the more RBP is added, the more obvious the strength of cement mortar will decrease; when RBP When the blending amount is 50\%, the strength of cement mortar is less than $50 \%$ of that without regenerated fine powder. The particle size of the regenerated micro-powder has a certain effect on its activity. After a certain period of ball milling, the activity of RCP can be effectively increased. However, if the ball milling time is too long, the particles will be too fine and the RCP activity will decrease. The activity of RBP increased slightly with the increase of ball milling time, but after more than $1 \mathrm{~h}$, the effect gradually weakened.

\section{Acknowledgements}

This work was sponsored by Jinhua Science and Technology Research Project [No.2020-494], and "University enterprise cooperation project" of visiting engineers in universities [No. FG2020015].

\section{Reference}

[1] XIAO J Z,LI W G,FAN Y H, et al. An overview of study on recycled aggregate concrete in China (1996 -2011) [J]. Construction and Building Materials, 2012, 31: 364-383.

[2] ZHAO W,LEEFTINK R B,ROTTER V S.Evaluation of the economic feasibility for the recycling of construction and demolition waste in China-The case of Chongqing[J]. Resources, Conservation and Recycling, 2010, 54(6): 377-389.

[3] SUN Z,LIU F,T ONG T, et al. Hydration of Concrete Containing Hybrid Recycled Demolition Powders [J]. Journal of Materials in Civil Engineering, 2017. 29(7): 401407. 
[4] LIU Q,TONG T,LIU S H,et al. Investigation of using hybrid recycled powder from demolished concrete solids and clay bricks as a pozzolanic supplement for cement [J]. Construction and Building Materials, 2014, 73(30): 754-763.

[5] KIM Y J,CHOI Y W. Utilization of waste concrete powder as a substitution material for cement [J].Construction and Building Materials, 2012, 30(5): 500-504.

[6] Kecebas A, Kayveci M. Effect on optimum insulation thickness, cost and saving of storage design temperature in cold storage in Turkey $[\mathrm{J}]$. Energy Education Science and Technology Part A Energy Science and Research, 2010, 25: 117-127.

[7] XU L H, DENG F Q,CHI Y. Nano-mechanical behavior of the interfacial transition zone between steel-polypropylene fiber and cement paste [J]. Construction and Building Materials, 2017, 145(1): 619-638.

[8] ZADEH V Z, BOBKO C P. Nano -mechanical properties of internally cured kenaf fiber reinforced concrete using nanoindentation [J]. Cement and Concrete Composites, 2014, 52(9): 9-17.

[9] HU C L,LI Z J. Property investigation of individual phases in cementitious composites containing silica fume and fly ash[J].Cement and Concrete Composites,2015,57(3):1726.

[10] SORELLI L,CONSTANTINIDES G,ULM F J,et al.The nano-mechanical signature of Ultra High Performance Concrete by statistical nanoindentation techniques [J]. Cement and Concrete Research, 2008, 38(12): 1447-1456.

[11]ZHANG Y, ZHU P,LIAO Z Q, et al. Interfacial bond properties between normal strength concrete substrate and ultra -high performance concrete as a repair material [J]. Construction and Building Materials, 2020, 235(28): 117431. 